\title{
Migrant Background and Higher Education Participation in Europe: The Effect of the Educational Systems
}

\author{
Dorit Griga ${ }^{1, \star}$ and Andreas Hadjar ${ }^{2}$
}

\begin{abstract}
The main aim of this article is to shed light on the extent to which differences in higher education participation between people with and without a migrant background of low/higher social origin can be explained by two macro-level characteristics of national educational institutions: stratification of the secondary school system and provision of alternative access to higher education. General assumptions are that people with a migrant background of low social origin benefit in lowstratified secondary school systems and in systems that provide alternative access to institutions of higher education more than their native peers in the same social stratum, owing to primary and secondary effects of migrant background. Database is a pooled dataset of the five waves of the European Social Survey. Results of logistic multi-level analyses indicate that a low-stratified secondary school system improves the probability of people with a migrant background/low social origin attaining a higher education degree. On the other hand, a stratified secondary school system reduces their chances regarding this educational stage. The provision of alternative access to an institution of higher education improves their likelihood of becoming higher education graduates.
\end{abstract}

\section{Introduction}

In the majority of European countries, school students with a migrant background are disadvantaged in the educational system (PISA 2003, 2009; Levels et al., 2008). Given their lower performance in school, students with a migrant background are also underrepresented in many higher education (HE) systems. An exception is the United Kingdom, where participation of ethnic minority groups in $\mathrm{HE}$ exceeds that of non-migrants (Connor et al., 2004; Chowdry et al., 2008). ${ }^{1}$ For many European countries, immigration has proven to be bimodal, with a substantial share of the foreign-born population bringing in high human capital on the one hand, and on the other hand, many children of immigrants grow up in homes where their parents have only low levels of education by the standards of the receiving society and speak in their mother tongue with their children (Alba et al., 2011).

Considering the state-of-the-art in empirical migration research, there is a lack of studies that analyse educational inequalities related to migrant background focusing on macro-level factors. Countries differ considerably in the organization of their educational systems, and some article investigate the extent to which particular educational institutions foster or reduce inequalities among students of different social origins (Dronkers and Fleischmann, 2010; Dronkers and de Heus, 2010; Van de Werfhorst and Mijs, 2010; Dronkers et al., 2012). Although it is often taken into account that migrant-specific disadvantages are intertwined with disadvantages related to social origin (Kristen and Granato, 2007; Kristen and Dollmann, 2010), and controls for social origin are included in the models of analysis, the focus has mainly remained on a universal effect of migrant background not taking into account variations among migrant groups. However, assuming inequalities at the intersection between social origin and migrant background, in our article, migrant groups are differentiated by social origin. Claiming that migrant background and social origin do not function independently of one another, but interrelate instead, the presented

\footnotetext{
${ }^{1}$ Department of Sociology of Education, Institute of Educational Science, University of Bern, CH-3012 Bern, Switzerland and ${ }^{2}$ Institute of Education \& Society, University of Luxembourg, L-7220 Walferdange, Luxembourg.

${ }^{\star}$ Corresponding author. Email: dorit.griga@edu.unibe.ch 
study focuses on disadvantaged migrant groups. Because youths with a migrant background suffer language problems and differ in their educational choices from non-migrants (primary and secondary effects of migrant origin-as outlined later), we expect youths with a migrant background of low social origin to be more sensitive than non-migrants to the structure of the educational system of the countries of destination. In contrast, for children who have a high social status, no disadvantages are expected regarding their educational career because they can rely on sufficient cultural, economic, and social capital.

With regard to other determinants of inequalities in educational attainment, social origin in terms of parental educational level or occupational status has also proven to be positively correlated with further indicators explaining the variations in educational success of different migrant groups (cf. Becker, 2011)-e.g., proficiency in the official language in the country of destination (Esser, 2006), social capital of immigrants (Zhou and Bankston, 1994), or legal status (Flores, 2010; Söhn, 2011).

The analysis presented here addresses inequalities between second-generation migrant groups and nonmigrant groups of the same social origin in HE-taking into account macro-level characteristics of different educational systems. We focus on second-generation migrants, as their educational attainment has become a decisive indicator for intergenerational immigrant integration (Heath et al. 2008; Fleischmann et al. 2013). We differentiate between migrants of low and of higher social origin as well as non-migrants of low and higher social origin. We aim to answer the following question: How do characteristics of the educational systems shape the differences between people with a migrant background of low social origin and the reference group of non-migrants of low social origin regarding the chances to attain an $\mathrm{HE}$ degree. Comparing different institutional settings, the article focuses specifically on the stratification of the secondary school system and the provision of alternative access to $\mathrm{HE}$.

\section{Theoretical Framework and Hypotheses}

In the following section, a general approach to explain educational inequalities related to social origin is presented and applied to migrant-specific inequalities. Then the links between characteristics of the educational systems and migrant-specific inequalities are theorized.

\section{Educational Inequalities along the Axes of Social and Migrant Origin}

Framing an analysis of educational inequalities, two main theoretical approaches are commonly used in sociology of education: Whereas Bourdieu and Passeron (1977) focus on socialized habits and resources from the perspective of conflict theory, rational-choice approaches (Erikson and Jonsson, 1996; Breen and Goldthorpe, 1997) based on the concept of educational transitions by Mare (1980) refer to educational decisions being based on cost-benefit calculations. For the study of inequalities of participation in HE, the concept of primary and secondary effects of social origin (Boudon, 1974) seems to be suitable, as in addition to social origin, the concept has recently been extended to capture primary and secondary effects of migrant origin, too (Van de Werfhorst and Van Tubergen, 2007; Kristen and Dollmann, 2010). Therefore, the concept can be used to explain differences in educational outcomes between social strata as well as migrant and non-migrant groups. According to the classical approach of Boudon (1974), primary effects of social origin describe educational differences that are the result of socially biased performance levels that originate from class-specific differences in parental support or learning environments. Secondary effects of social origin relate to differences in transition behaviour-educational decisions-that persist after controlling for school performance and may result from group-specific educational aspirations. With regard to primary effects of migrant origin, for many migrants, the official language in the country of destination is not their native language. As a consequence, the native language often remains the language spoken at home. Because language skills in the official language in school are essential for educational success, these children encounter language barriers in school (cf. PISA studies; OECD, 2006). Even in the case that the official language is spoken by a specific migrant group as their mother tongue, migrant parents may be less able than non-migrants to support their children's learning, as many teaching and learning contents (e.g., history, art, or ethics) are nation-, region-, or culture-specific. In the few studies that focus on secondary effects (controlling for socioeconomic background and previous performances), higher transition rates of youths with a migrant background - and mostly low social origin - are revealed in the more demanding educational tracks available. This applies to both the transition to upper secondary education and HE (for England and Wales: Jackson, 2012; and Sweden: Jackson et al., 2012; for upper secondary education in Finland: Kilpi-Jakonen, 2011; and for HE in Germany: Kristen et al., 2008; and 
Switzerland: Griga, 2014). To explain the observed findings, several studies in the United States (Kao and Tienda, 1998), France (Brinbaum and Cebolla-Boado, 2007), and The Netherlands (Van de Werfhorst and Van Tubergen, 2007) revealed that students of a migrant origin exhibit higher educational aspirations than their non-migrant counterparts. Another argument is that students with a migrant background might (more often than non-migrants) perceive staying in education as an alternative to being unemployed or precariously employed. This could be the case if students with a migrant background are less well-informed about alternatives to HE-e.g., vocational education-or if they expect (or experience) discrimination in the labour market (Kristen et al., 2008). Indeed, a study conducted in Switzerland by Fibbi et al. (2006) revealed a lower chance of being invited for job interviews when searching for an apprenticeship for some migrant groups of low social origin.

\section{Macro-Level Influences: Stratification of the Secondary School System and Alternative Access to $\mathrm{HE}$}

The effects of individual and family characteristics as well as migrant background may differ between countries. In the analysis of differences between countries with regard to educational inequalities between social classes, the stratification of the secondary school system is often cited as one explanation. The term stratification refers to the degree to which educational systems have clearly differentiated types of schools whose curricula are defined as 'higher' or 'lower' (Allmendinger, 1989). One typical feature of highly stratified school systems is early tracking; i.e., separating pupils into different school tracks. If primary effects of social origin (Boudon, 1974) are assumed, it seems plausible that under the condition of early tracking-due to their lower performancesstudents with a disadvantaged social background will be underrepresented in schools that award the (full) HE entrance qualification to their graduates. Studies that confirmed the unbalanced distribution of pupils of different social origins in the different school tracks in stratified secondary school systems were conducted by Blossfeld and Shavit (1993), Horn (2008), and Becker (2009). In line with this, Brunello and Checci (2007) show for a number of educational outcomes, how the effect of family background increases with length of time spent in tracked schools-determined by age of first selection. Summing these studies up, educational inequalities related to social origin tend to be smaller in comprehensive school systems, while highly stratified secondary school systems rather increase educational inequalities. Institutional settings of the educational systems are thereby linked to type of welfare regime (cf. Esping-Andersen, 1990; Hega and Hokenmaier, 2002; Hadjar and Berger, 2011), with the social-democratic type favouring comprehensive school systems (e.g., Denmark, Finland, Norway, Sweden), while in conservative regimes, a high degree of stratification in the school systems facilitates inequalities (e.g., Austria, West Germany). Moreover, with regard to students with both a disadvantaged social origin and a migrant background, the question arises whether in stratified secondary school systems - due to primary effects of migrant origin-these students encounter additional barriers compared with non-migrants whose social origin is equally low. Although some studies have found that stratified school systems tend to magnify existing inequalities in the educational performance between students with a migrant background and students without a migrant background (Van de Werfhorst and Mijs, 2010), it is of interest to analyse how the degree of stratification of the secondary school system affects educational chances of migrants and non-migrants of the same social origin. In countries with a low-stratified school system-given the absence of early branching points and due to an increased time-span available for keeping up with their native peers-youths with a migrant background of a low social origin are thus expected to attain more often an upper secondary school certificate than in countries with more stratified school systems. As-ceteris paribus - a higher number of eligible youths with a migrant background and being of low social origin result in increased transition to $\mathrm{HE}$ as well as increased numbers of HE graduates, higher chances to attain an HE degree could be expected for this group (compared with nonmigrants of the same social origin) in countries with low-stratified secondary school systems.

Following Erikson and Jonsson (1996), removing barriers and educational dead-ends as well as introducing measures that facilitate permeability in the educational system-i.e., providing alternative access to $\mathrm{HE}$ - is an effective option to reduce educational inequalities. Claiming that the influence of social origin decreases over the life course (Blossfeld and Shavit, 1993), we assume that inequalities in $\mathrm{HE}$ should be smaller in countries with opportunities for alternative access to HE. In Europe, such opportunities are, for example, provided in Finland, Sweden (social-democratic welfare regimes, less-stratified school systems, Table 1), Great Britain (liberal welfare regime, low-stratified school system), and Ireland (predominantly liberal welfare state, mediumstratified school system). In these countries, talented youths of lower social origin, who choose a vocational track, will still have the opportunity to continue to university, if they become more aware of their potential 
Table 1 Sample description and country characteristics

\begin{tabular}{|c|c|c|c|c|}
\hline Country* & Sample, $N$ & $\begin{array}{c}\text { People with } \\
\text { a migrant } \\
\text { background, } \\
\text { second-generation } \\
\text { (in the sample, } N \text { ) }\end{array}$ & $\begin{array}{c}\text { Age of } \\
\text { selection } \\
\text { (low } \\
\text { stratification) } \\
\text { in the 1980s }\end{array}$ & $\begin{array}{l}\text { Alternative } \\
\text { access to } \mathrm{HE}\end{array}$ \\
\hline
\end{tabular}

\begin{tabular}{|c|c|c|c|c|c|}
\hline Austria (AT) & 4,852 & 488 & 10 & Low & 11.2 \\
\hline Belgium (BE) & 6,054 & 525 & 12 & Low & 34.8 \\
\hline Bulgaria (BG) & $5^{\prime} 067$ & 139 & 14 & Low & 24.0 \\
\hline Czech Republic (CZ) & 6,799 & 439 & 15 & Low & 12.2 \\
\hline Denmark (DK) & 5,896 & 287 & 16 & Low & 46.1 \\
\hline East Germany (DE-E) & 3,974 & 247 & 16 & Low & 31.8 \\
\hline Finland (FI) & 7,576 & 125 & 16 & High & 38.8 \\
\hline France (FR) & 6,676 & 764 & 16 & Low & 30.6 \\
\hline Great Britain (GB) & 7,913 & 569 & 16 & High & 39.2 \\
\hline Greece (GR) & 5,225 & 432 & 14.5 & Low & 21.9 \\
\hline Hungary (HU) & 5,978 & 277 & 10 & Low & 18.3 \\
\hline Ireland (IE) & 5,494 & 173 & 12 & High & 35.8 \\
\hline Israel (IL) & 2,892 & 1,809 & 12 & Low & 41.1 \\
\hline Luxembourg (LU) & 1,505 & 343 & 12 & Low & 17.4 \\
\hline The Netherlands (NL) & 7,554 & 438 & 12 & Low & 29.8 \\
\hline Norway $(\mathrm{NO})$ & 6,336 & 235 & 16 & Low & 41.2 \\
\hline Poland (PL) & 6,208 & 291 & 15 & Low & 17.2 \\
\hline Portugal (PT) & 7,925 & 114 & 15 & Low & 12.5 \\
\hline Sweden (SE) & 6,313 & 484 & 16 & High & 32.2 \\
\hline Switzerland $(\mathrm{CH})$ & 6,091 & 870 & 15.5 & Low & 31.6 \\
\hline West Germany (DE-W) & 6,611 & 517 & 10 & Low & 31.0 \\
\hline
\end{tabular}

Israel was additionally included in the ESS data because of its structural closeness (economic and educational system) to Europe.

(Erikson and Jonsson, 1996). One way of implementing such flexibility at the transition to HE is a less-strict division between academic and vocation-oriented schools, so that students graduating from a vocationoriented school are not excluded from entering $\mathrm{HE}$ at a later date ('third chances'). ${ }^{2}$ Institutional settings that provide opportunities for alternative access thereby usually introduce measures that take into account students' learning and work experience since leaving school. According to Orr et al. (2011), in recent years, many developments in the area of recognition of previous learning and work experience have occurred across Europe. For example in Sweden, nearly every third student uses an alternative route to enter an institution of HE. However, the large majority of students in Europe still enter HE on a direct path. Comparing the number of students with a disadvantaged social background entering HE via alternative access opportunities with that of those entering HE via the traditional route does not reveal a consistent pattern. Accordingly, in only 9 of 12 countries considered here (Eurostudent; cf. Orr et al., 2011), the shares of students with a low socioeconomic background entering HE via alternative access are higher than in the traditional route. Even in these cases, students with an advantaged background could still have an increased likelihood to enter HE than students of low social origin. Hence, existing studies focusing on the taking up of 'second chances' revealed that they are more often taken up by people of privileged social origin (Hillmert and Jacob, 2005). However, it is not clear whether this also applies to youths with a migrant background. Thus, for Germany, there is some evidence that 'second chances' to obtain an upper secondary school leaving certificate may reduce educational inequalities related to migrant background (Burkhart et al., 2011). Given the secondary effects of migrant origin observed at other transitions, it seems plausible to expect that-once they are given a 'third chance' to enter an institution of HE-these youths will more often than non-migrants of the same social strata decide in favour of taking up these opportunities. ${ }^{3}$ Taking these considerations into account, it will also be asked if migrants of low social origin benefit from the provision of alternative access opportunities to HE to a larger extent than non-migrants of an equally disadvantaged social origin due to their high 
educational aspirations (secondary effects of migrant origin).

\section{Hypotheses}

Drawing on the concept of primary and secondary effects of social origin (Boudon, 1974) as well as its recent application to primary and secondary effects of migrant origin (Kristen and Dollmann, 2010), two hypotheses are derived. First, in countries with a low-stratified secondary school system, we expect people with a migrant background whose social origin is disadvantaged to attain an HE degree more often (compared with their native peers whose social origin is equally low) than in countries with a higher degree of stratification in the secondary school system (H1). Second, we assume that also the provision of alternative access to HE institutions has a positive effect on the likelihood of people with a migrant background/low social origin to attain an HE degree (compared with non-migrants of low social origin) (H2).

\section{Data and Methods}

\section{European Social Survey}

The selected database is the cumulated European Social Survey (ESS). The ESS is a repeated cross-sectional survey in up to 30 countries. Because the minimum number of cases per wave and country is rather small, we used the pooled dataset of the five waves collected so far. Although some minority groups and groups of people with a migrant background can be underrepresented in the survey (cf. for Switzerland: Laganà et al., 2013), the resulting bias is tolerable, as we focus on mechanisms rather than absolute frequencies.

\section{Selection of Countries and Cases}

Among the countries that were included in the ESS cumulative dataset (Rounds 1-4) and ESS 5, six countries (Cyprus, Estonia, Italy, Russia, Slovenia, and Ukraine) were excluded owing to data problems, a low number of people with a migrant background (below 100) or difficulty in operationalizing migrant background. Among people with a migrant background, only second-generation migrants were included, because they spent the whole of their educational cycle in the country of destination. Because our research question focuses on the attainment of an HE degree, only those people were considered in the analysis who were old enough to have obtained an HE degree. Comparative studies show that students typically finish their studies at the age of 28. Only a small number of HE graduates finish their studies at a higher age (Orr, 2008). To ensure that almost no one was still studying and to prevent selection effects of higher ages, only people aged between 29 and 85 were included in the analysis. Table 1 includes information on the number of cases (including second-generation migrants) per country who met these criteria.

\section{Methods}

Multi-level techniques are employed, as using conventional individual-level techniques (such as ordinary least squares regression) would not be adequate to analyse data that are clustered in countries. Using multi-level modelling guarantees that standard errors of the macrolevel effects will not be underestimated. Consequently parameters will not appear to be unduly significant (Raudenbush and Bryk, 2002). Because the dependent variable is a dummy variable (HE degree attained vs. not attained, see later), logistic multi-level models are estimated. Although we are aware of the criticism of odds ratios (ORs) (Mood, 2010; Hinz and Auspurg, 2011), we stick to the method commonly used in educational sociology (Blossfeld, 1993; Breen and Goldthorpe, 1999) to analyse differences in educational opportunities referring to ORs. Despite the criticisms, ORs (Erikson and Goldthorpe, 2002) still provide a good insight into educational inequalities, as they reveal the chances of a specific group attaining an HE degree compared with another group. Considering the unobserved heterogeneity problem, results of the data analysis presented later are only interpreted with regard to significance and direction (and not regarding the absolute score of the coefficient).

\section{Operationalization of Variables}

The attainment of an HE degree is used as the dependent variable. The binary variable was coded ' 1 ', if the highest educational attainment of a person was classified as ISCED 5 or 6. Instead of including migrant background and socioeconomic origin as two separate variables, we keep up with our argument that migrant and social origin do not influence educational chances independent from one another. Hence, differentiating between four social groups that combine the parameter values of the two variables allows us to analyse chances of people with and without a migrant background of the same social origin and in varying educational systems simultaneously. We therefore distinguish between people with and without a (second-generation) migrant background of low and higher social origin (migrant background/low social 
origin, non-migrant background/low social origin, migrant background/higher social origin, non-migrant background/higher social origin). ${ }^{4}$ A migrant background was coded 1 if one or both parents were born in a foreign country while the respondent was born in the country of destination, thereby excluding first-generation migrants from the analysis. A low social origin was coded if the highest educational level attained by a respondent's parents was ISCED 2 or lower; a higher social origin if the highest educational level attained by parents was higher than ISCED 2. The respondent's year of birth was included to control for cohort effects. Finally, a dummy variable for female respondents and four dummy variables for the different waves were included as controls.

At the macro level, the degree of stratification of the secondary school system was measured via the age of selection into different tracks of secondary schools (following Brunello and Checci, 2007). An advantage of age of selection compared with other (metric) variables to operationalize stratification is that this countryspecific characteristic has been rather stable over the past decades and therefore applies to most of the birth cohorts covered in the analyses. ${ }^{5}$

As another explanatory variable at the country level, the provision of alternative access to $\mathrm{HE}$ was coded as a dummy variable. Value 1 was applied, if alternative access to HE has been introduced early in a country and the proportion of students who had entered $\mathrm{HE}$ via an alternative route exceeded 20 per cent in $2008 .^{6}$ To decide whether a country met one of these criteria, data from Orr et al. (2011) and the Eurydice information on national educational systems (European Commission, 2012) were used. Finally, size of HE system was included as a control variable in the models taking into account the argument that (quantitative) inequalities in the attainments of educational degrees between social groups are accounted for by performance, educational choice, as well as the size of different levels of the educational system (Erikson and Jonsson, 1996). Moreover, controlling for size enabled capturing the genuine effects of the explanatory variables, which of course are connected to the sizes of the HE systems. ${ }^{7}$ The variable was operationalized by the percentage of people aged 29-65 (among the cases considered in the analysis; see earlier) who had obtained an $\mathrm{HE}$ degree. Both metric variables at the country level (stratification of the secondary school system, alternative access to $\mathrm{HE}$ ) were mean centred before running the models.

\section{Results}

Before presenting multi-level results, we will look at migrant-specific advantages and disadvantages by country.

\section{Migrant Background, Social Origin, and HE}

In Figure 1, the relative chances of (second-generation) migrant groups as well as non-migrant groups attaining an HE degree are shown. Compared with people without a migrant background and of low social origin, both people with and without a migrant background whose social origin is advantaged exhibit a higher likelihood of attaining an HE degree in all European countries (and Israel) included in the analysis.

If people with a migrant background of low social origin are compared with their native peers whose social origin is equally low, the pattern is less clear: They are significantly more successful than the latter in Israel, East Germany, and Great Britain. On the other hand, those in Belgium have significantly less chance of attaining an $\mathrm{HE}$ degree than their native peers whose social origin is equally low. What do these first results show regarding the effects of different educational systems? A visual inspection of the results rather indicates disadvantages for migrants of low social origin in countries with a highly stratified secondary educational system-often combined with a conservative welfare regime with a low social mobility level_and advantages for migrants in less-stratified educational systems like in the Scandinavian social-democratic welfare states (Denmark, Finland, Norway, and Sweden) being very much in favour of equality. Also, educational inequalities observed between the social strata appear to be moderate.

\section{Multivariate Results}

In Model 1 (Table 2), controlling only for micro-level characteristics, an increased probability to attain an $\mathrm{HE}$ degree is observed for both groups of people with a migrant background-of low (OR 1.10) and higher social origin (OR 4.56)-compared with natives of low social origin. ${ }^{8}$

In Model 2, the stratification of the secondary school system and size of $\mathrm{HE}$ system were included. Interpreting the main effect of the explanatory variable at the macro level, a high age of selection alone does not improve the relative chances of people without a migrant background with low social origin to attain an $\mathrm{HE}$ degree compared with their peers in school systems with a low age of selection but an equally large HE system. Instead, relative chances for those without a migrant background and low social origin rise if size of $\mathrm{HE}$ system is large (OR 1.06). The cross-level interaction coefficient "Migrant background with low social origin $\mathrm{x}$ (Low) Stratification: age of selection" supports hypothesis 1-the assumption that people with a migrant background/low social origin exhibit higher propensities 


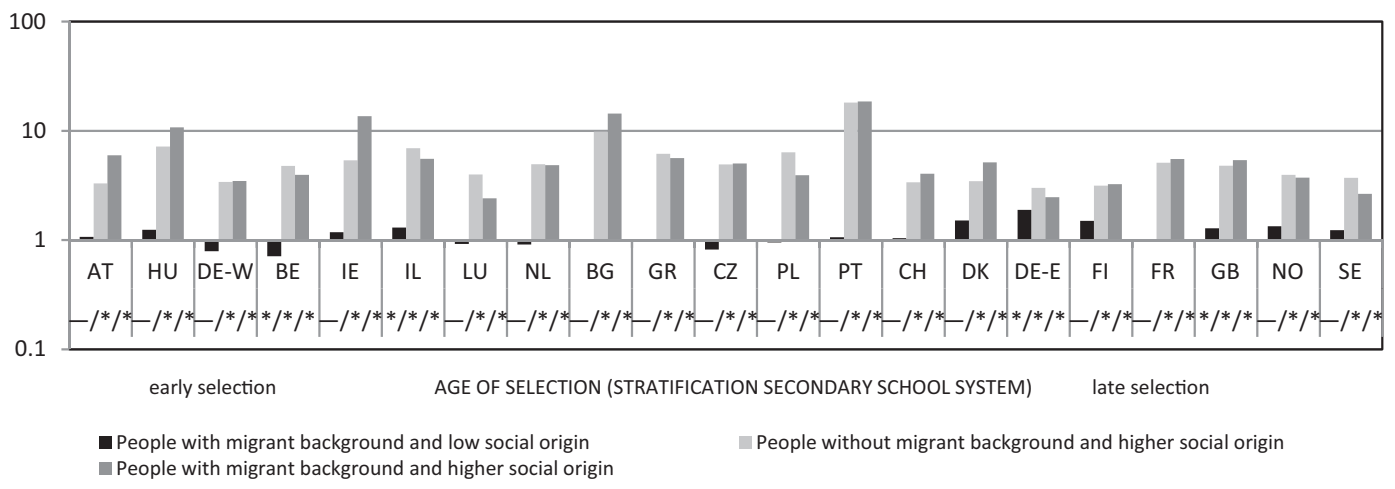

Figure 1 Chances of migrant and non-migrant groups to attain an HE degree (ref. people without a migrant background and low social origin), odds ratios ${ }^{11}$.

Data Source: ESS 2002-2010 (people aged 29-85, people without a migrant background and people with a migrant background, 2nd generation), controlled for gender, year of birth and wave.

than their native peers whose social origin is equally low in terms of attaining an HE degree in countries with a low stratified secondary school system. Considering the number of only 21 macro units/countries, the significance level of the corresponding OR of 1.03 is reasonable. Looking at further cross-level interactions, a large size of the HE system slightly decreases the effect of a higher social origin on chances of non-migrants to attain an HE degree thereby reducing the gap between people without a migrant background of low/higher social origin.

The provision of alternative access to HE serves as the main explanatory variable at the macro level in model 3 . In countries where such opportunities are provided nonmigrants with a low social origin exhibit an increased likelihood of attaining an HE degree compared to their peers in other countries with an equally large HE system (OR 1.39). In Hypothesis 2, we expected additional benefits of such opportunities for people with a migrant background/low social origin compared with non-migrants whose social origin is equally low regarding their chances to participate in HE. As indicated by the corresponding OR of 1.22, the hypothesis is backed by the data. Given increased options at this educational transition-e.g., a 'third chance' to attain an HE degree-the educational chances for often high-aspiring people with a migrant background/low social origin improve more markedly than those of non-migrants/low social origin. A finding beyond our hypothesis is that native people with a higher social background also have additional benefits from the provision of alternative access to institutions of HE compared with non-migrants with a lower social origin, providing empirical evidence that-as in the case of 'second chances'-among non- migrants, alternative pathways to HE ('third chances') are more often taken up by people with advantaged social origins. No additional benefits were revealed, however, for the group of people with a migrant background/higher social origin compared with nonmigrants/low social origin. Moreover, a larger size of the HE system decreases the positive effect of a higher social origin on the chances to attain an HE degree of people with and without a migrant background compared with non-migrants of low social origin.

\section{Discussion}

This article aimed to shed light on the question to what extent the chances of people with a migrant background to attain an HE degree are influenced by macro-level characteristics of national educational institutions, namely, stratification of the secondary school system and provision of alternative access to HE.

Following our argument, that owing to primary and secondary effects of migrant origin such youths-if they are of a disadvantaged social origin too-are more sensitive to varying characteristics of the national educational institutions than non-migrants whose social origin is equally low, we distinguished between people with and without a migrant background of low social origin and people with and without a migrant background of higher social origin.

The chances to attain an HE degree of the different groups were compared with those of people without a migrant background of low social origin.

Our results show that the two characteristics of national educational systems investigated in this article do indeed affect inequalities in HE between specific 
Table 2 Logistic multi-level model (unit-specific model), dependent variable: higher education degree, HLM results

Odds ratios

Micro level (individual)

Migrant background

Migrant/low social origin

Without migrant/higher social origin

Migrant/higher social origin

Female (Ref: male)

Year of birth

Waves (Ref: 2002)

2004

2006

2008

2010

Macro level (country)

(Low) Stratification: age of selection

Alternative access to $\mathrm{HE}$

Size of HE system

Migrant background with low social origin

(Low) Stratification: age of selection

Alternative access to $\mathrm{HE}$

Size of HE system

Without migrant background with higher social origin

(Low) Stratification: age of selection

Alternative access to HE

Size of HE system

Migrant background with higher social origin

(Low) Stratification: age of selection

Alternative access to $\mathrm{HE}$

Size of HE system

Constant

Random effects

$\sigma^{2}$

$\tau$

Model fit

Chi-quadrat/df/P
Model 1

Model 2

Model 3

\begin{tabular}{|c|c|c|}
\hline $1.10^{*}$ & 1.07 & 1.02 \\
\hline $4.31^{\star * *}$ & $4.46^{\star * *}$ & $4.38^{\star * *}$ \\
\hline $4.56^{\star * *}$ & $4.64^{\star * *}$ & $4.66^{* * *}$ \\
\hline $0.91^{\star * *}$ & $0.91^{\star * *}$ & $0.91^{* * *}$ \\
\hline $1.02^{* * *}$ & $1.02^{\star * *}$ & $1.02^{* * *}$ \\
\hline $0.95^{\star}$ & $0.95^{\star}$ & $0.95^{*}$ \\
\hline 1.02 & 1.02 & 1.01 \\
\hline $1.15^{\star * \star}$ & $1.15^{\star \star \star}$ & $1.15^{* * *}$ \\
\hline \multirow[t]{13}{*}{$1.87^{* * *}$} & $1.87^{\star * *}$ & $1.86^{* * *}$ \\
\hline & 1.02 & \\
\hline & & $1.39 \dagger$ \\
\hline & & \\
\hline & $1.03 \dagger$ & \\
\hline & & $1.22^{\star}$ \\
\hline & 1.01 & 1.00 \\
\hline & 1.00 & \\
\hline & & $1.09^{\star}$ \\
\hline & $0.99^{\star * *}$ & $0.99^{* * *}$ \\
\hline & $0.96^{*}$ & \\
\hline & & 1.02 \\
\hline & 0.99 & $0.99^{\star}$ \\
\hline$-1.90^{* \star *}$ & $-1.92^{\star * *}$ & $-1.97^{\star * *}$ \\
\hline 0.99 & 1.00 & 1.00 \\
\hline 0.38 & 0.10 & 0.07 \\
\hline
\end{tabular}

Nullmodell $\sigma^{2}=1.00 ; \tau=0.33$; chi-quadrat/df/P: 5848/20/***, significance levels: ${ }^{\dagger} \leq 0.10 ;{ }^{*} \leq 0.05 ;{ }^{* *} \leq 0.01 ;{ }^{* * *} \leq 0.001$.

Data Source: ESS 2002-2010 (people aged 29-85, people without a migrant background and people with a migrant background, second generation), Level-1, $n=122,939 ;$ Level-2, $n=21$, distribution on Level 1: Bernoulli, own calculations.

migrant and non-migrants groups. Results of logistic multi-level analyses indicated that a low-stratified secondary school system-as it is prevalent in the Scandinavian welfare states (e.g., Finland, Sweden) and as it used to be in many former state-socialist countries (East Germany)-improves the probability of people with a migrant background/low social origin to attain an HE degree compared with non-migrants whose social origin is equally low. Vice versa, a highly stratified secondary school system-as it is prevalent in many conservative welfare regimes (e.g., Austria, West Germany)-reduces their chances of attaining an HE degree compared with the reference group. This backs the theoretical argument that in low-stratified school systems (with a late age of selection), primary effects of migrant origin-for example, language problems that cause an overrepresentation of youths with a migrant background/low social origin in low-level secondary schools-are smaller. In addition, our data indicate that students with a migrant background of low social origin benefit from opportunities for alternative access to HE (in Finland, Great Britain, Ireland, Sweden) to a larger extent than non-migrants from the same social origin. Referring to the theoretical framework again, this is presumably due to secondary effects of migrant origin (Van de Werfhorst and Van Tubergen, 2007; Kristen and 
Dollmann, 2010), i.e., the higher educational aspirations of youths with a migrant background. Such provisions may improve the chances of people with a migrant background/low social origin (compared with nonmigrants/low social origin) and serve them as a stepping-stone to HE. With regard to policy recommendations, our results suggest reducing stratification in the secondary school system, e.g., by increasing the age of selection or abolishing low-demanding secondary schools that function as educational dead-ends, as well as facilitating permeability at the different educational stages. This may improve the chances of people with a migrant background and disadvantaged social origin to fully develop their talents.

However, the discovered inequality patterns might not only be structured by the stratification of the (secondary) educational system and alternative access opportunities, but partly originate from characteristics of the welfare regime or integration policies (as measured by MIPEX) being related to institutional settings of the educational systems. This does not contradict our findings, as both a low degree of stratification in the secondary school system and alternative access opportunities might be typical instruments of social-democratic welfare regimes and of countries with migrant-friendly policies.

Another factor behind the country-specific differences in migrants' access to HE is presumably the composition of the immigrant population in the different countries. For example, if the majority of the migrant population speaks the same language as the native population, differences in HE access might be minimal. Although country of origin and language in particular are important factors of educational attainment on the micro level (cf. Dronkers and Fleischmann, 2010), the macro-factors under consideration (stratification of the secondary school system, alternative access to HE, size of HE system) do not seem to be systematically linked to the composition of the migrant population according to OECD data (OECD, 2006). ${ }^{9}$

Interpreting the results of this study, however, several limitations have to be taken into account. Within the heterogeneous group of people with a migrant background, we only considered second-generation migrants and among them only differentiated between people of low and higher social origin, respectively. Despite the correlation between social origin and other factors determining educational success being observed in many European countries, results may be biased because of compositional effects of the migrant populations and interactions with specific countries of destination. Future research should thus aim at taking further characteristics (e.g., country of origin, reason for migration, legal status) as well as interactions with the countries of destination into account.

Concerning macro-level effects and cross-level interactions, the inclusion of more macro-level units (countries) would increase the significance of the estimated effects, although even these results provided substantial support for our hypotheses. Notwithstanding the tight ratio between macro-level predictors and macro-level units (countries) per model ${ }^{10}$ and the fact that the countries included in the analysis were not a random selection, both the approach and the results obtained were confirmed by several robustness checks. Thus, additional models that were estimated on a basis of a randomly reduced dataset (e.g., excluding France, Ireland, and West Germany from the sample) produced the same results. Specifically regarding the stratification of the secondary school system, both the use of different measures (e.g., a categorical stratification variable, a metric variable indicating the fraction of primary and secondary education in tracking) as well as simultaneously controlling for former state-socialist countries confirmed the results.

All in all, by looking at migrant and non-migrant groups of low social origin simultaneously, we were able to investigate interactions between a migrant background on the one hand and the characteristics of educational systems of the countries of destination on the other hand. The characteristics of the educational system turned out to be of importance for the integration of students with a migrant background into the HE system. A reduction of migrant-specific inequalities regarding people with both a migrant background and a disadvantaged social origin seems more likely when the stratification of the secondary school system is reduced and alternative opportunities to access the HE system are provided than when the size of the HE system is simply increased.

\section{Notes}

1 However, they are still underrepresented in the more prestigious institutions.

2 Thereby the provision of alternative access to HE ('third chances') is to be distinguished from socalled 'second chances' to attain the HE entrance certificate by means of additional schooling to receive or upgrade an upper secondary degree.

3 In contrast to vocational education, we do not expect information deficits in this context for youths with a migrant background Because 
measures of alternative access to $\mathrm{HE}$ are joined by enormous information campaigns regarding the target groups on the one hand, and they allow for putting into effect their high educational aspirations on the other hand.

4 With our approach, we attempt to make inequalities at the intersection between migrant background and social origin visible. Using these dummy variables allows an easy comparison between the social groups, with migrants of a low social origin being the main interest.

5 As validity tests regarding the stratification variable show, results using age of selection equal to a large extent results based on a categorical measure (differentiating medium/highly-stratified secondary school systems and low-stratified secondary school systems following concepts of Müller and Shavit, 1998 and Hadjar and Berger, 2010).

6 The threshold was set after reviewing the different educational systems. There are many systems with small proportions of students who entered the HE system via alternative access, but in countries with a long tradition of alternative access, this proportion is above one-fifth of the student population.

7 Pearson correlation coefficients between the stratification and size of HE system: $r=0.31$, alternative access and size of HE system: $\mathrm{r}=0.38$, stratification and alternative access: $r=0.25$.

8 Robustness checks employing separate variables for social origin and migrant background confirmed increased chances to attain an HE degree for people with a migrant background and people with an advantaged social origin.

9 Given that the largest migrant groups in Belgium speak one of the Belgian official languages, this would imply lower disadvantages for migrants of low social origin. However, results indicate comparably strong disadvantages. For Denmark, results rather indicate a migrant advantage, even while the most important migrant groups originate from nonNorthern language backgrounds (Turkey, Pakistan, Germany; cf. OECD, 2006).

10 However, it is still an on-going debate how many units at Level 2 are necessary to generalize across these units. Although most authors recommend a larger sample, for example, Nezlek (2008) suggests that already $10 \mathrm{U}$ at Level 2 might be sufficient.
11 With regard to country comparisons, due to unobserved heterogeneity, the coefficients presented here should not be interpreted across models (see earlier, Mood, 2010).

\section{References}

Alba, R. D. and Waters, M. C. (Eds.), (2011). The Next Generation - Immigrant Youth in a Comparative Perspective. New York: New York University Press.

Allmendinger, J. (1989). Educational systems and labor market outcomes. European Sociological Review, 5, 231-250.

Becker, R. (2009). Entstehung und Reproduktion dauerhafter Bildungsungleichheiten. In Becker, R. (Ed.), Lehrbuch der Bildungssoziologie. Wiesbaden: VS Verlag für Sozialwissenschaften, pp. 86-129.

Becker, R. (Ed.), (2011). Integration durch Bildung: Bildungserwerb von jungen Migranten in Deutschland. Wiesbaden: VS Verlag für Sozialwissenschaften.

Blossfeld, H.-P. (1993). Changes in educational opportunities in the Federal Republic of Germany. In Shavit, Y. and Blossfeld, H.-P. (Eds.), Persistent Inequality. Boulder: Westview, pp. 51-74.

Blossfeld, H.-P. and Shavit, Y. (1993). Dauerhafte Bildungsungleichheiten. Zeitschrift für Pädagogik, 39, 25-52.

Boudon, R. (1974). Education, Opportunity, and Social Inequality. New York: Wiley.

Bourdieu, P. and Passeron, J. C. (1977). Reproduction in Education, Society and Culture. Beverly Hills: Sage.

Breen, R. and Goldthorpe, J. H. (1997). Explaining Educational Differentials. Towards A Formal Rational Action Theory. Rationality and Society, 9, 275-305.

Breen, R. and Goldthorpe, J. H. (1999). Class inequality and meritocracy. The British Journal of Sociology, 50, $1-27$.

Brinbaum, Y. and Cebolla-Boado, H. (2007). The school careers of ethnic minority youth in France. Ethnicities, 7, 445-474.

Brunello, G. and Checci, D. (2007). Does school tracking affect equality of opportunity? Economic Policy, 22, 781-861.

Burkhart, S., Heublein, U. and Wank, J. (2011). Bildungsinländer 2011. Bonn: DAAD.

Chowdry, H. et al. (2008). Widening Participation in Higher Education. IFS Working Paper No W10/04. Bonn: IZA.

Connor, H., Tyers, C. and Modood, T. (2004). Why the Difference? A Closer Look at higher education Minority 
Ethnic Students and Graduates. Research Report 552. London: Institute of Employment.

Dronkers, J. and de Heus, M. (2010). Negative selectivity of Europe's guest-workers immigration? In de Corte, E. and Fenstad, J. (Eds.), From Information to Knowledge, from Knowledge to Wisdom. London: Portland Press, pp. 89-104.

Dronkers, J. and Fleischmann, F. (2010). The educational attainment of second generation immigrants from different countries of origin in the EU-memberstates. In Dronkers, J. (Ed.), Quality and Inequality of Education. Cross-national Perspectives. Dordrecht: Springer, pp. 163-204.

Dronkers, J., van der Velden, R. and Dunne, A. (2012). Why are migrant students better off in certain types of educational systems or schools than in others? European Educational Research Journal, 11, 11-44.

Erikson, R. and Goldthorpe, J. H. (2002). Intergenerational inequality: a sociological perspective. Journal of Economic Perspectives, 16, 31-44.

Erikson, R. and Jonsson, J. O. (1996). Explaining class inequality in education: the Swedish test case. In Erikson, R. and Jonsson, J. O. (Eds.), Can Education be Equalized?. Stockholm: Westview Press, pp. 1-63.

Esping-Andersen, G. (1990). The Three Worlds of Welfare Capitalism. Princeton, NJ: Princeton University Press.

Esser, H. (2006). Migration, Language and Integration. AKI Research Review 4. Berlin: WZB (Social Science Research Center Berlin).

European Commission, Executive Agency, Audiovisual and Culture. (2012). Eurydice. Information on education systems and policies in Europe. In National Summary Sheets on Education Systems in Europe and Ongoing Reforms. European Commission. available from <http://eacea.ec.europa.eu/education/ eurydice/ $>$ [accessed 1 October 2013].

Fibbi, R., Lerch, M. and Wanner, P. (2006). Unemployment and discrimination against youth of immigrant origin in Switzerland. Journal of International Migration and Integration, 7, 351-366.

Fleischmann, F. et al. (2013). From ethnic capital to ethnic educational inequality. European Sociological Review, 29, 1239-1250.

Flores, S. M. (2010). State 'Dream Acts': The effect of instate resident tuition policies on the college enrollment of undocumented Latino students in the United States. Review of Higher Education, 33, 239-283.

Griga, D. (2014). Participation in higher education of youths with a migrant background in Switzerland. Swiss Journal of Sociology, 40, forthcoming.

Hadjar, A. and Berger, J. (2011). Geschlechtsspezifische Bildungsungleichheiten in Europa. In Hadjar, A.
(Ed.), Geschlechtsspezifische Bildungsungleichheiten. Wiesbaden: VS Verlag für Sozialwissenschaften, pp. 23-54.

Heath, A., Rothon, C. and Kilpi, E. (2008). The second generation in Western Europe. Annual Review of Sociology, 34, 211-235.

Hega, G. M. and Hokenmaier, K. G. (2002). The welfare state and education. German Political Studies, 2, 143-173.

Hillmert, S. and Jacob, M. (2005). Zweite chance im Schulsystem? In Berger, P. A. and Kahlert, H. (Eds.), Institutionalisierte Ungleichheiten. Weinheim: Juventa, pp. 155-176.

Hinz, T. and Auspurg, K. (2011). Gruppenvergleiche bei regressionen mit binären abhängigen Variablen. Zeitschrift für Soziologie, 40, 62-73.

Horn, D. (2008). Age of Selection Counts. Working Paper. Mannheim: MZES/Universität Mannheim.

Jackson, M. (2012). Bold choices. How ethnic inequalities in educational attainment are suppressed. Oxford Review of Education, 38, 189-208.

Jackson, M., Jonsson, J. O. and Rudolphi, K. (2012). Ethnic inequality and choice-driven educational systems. Sociology of Education, 85, 158-178.

Kao, G. and Tienda, M. (1995). Optimism and achievement: the educational performance of immigrant youth. Social Science Quarterly, 76, 1-19.

Kao, G. and Tienda, M. (1998). Educational aspirations of minority youth. American Journal of Education, 106, 349-384.

Kilpi-Jakonen, E. (2011). Continuation to upper secondary education in Finland. Acta Sociologica, 54, 77-106.

Kristen, C. and Dollmann, J. (2010). Sekundäre Effekte der ethnischen Herkunft. In Becker, B. and Reimer, D. (Eds.), Vom Kindergarten bis zur Hochschule. Wiesbaden: VS Verlag, pp. 117-144.

Kristen, C. and Granato, N. (2007). The educational attainment of the second generation in Germany. Ethnicities, 7, 343-366.

Kristen, C., Reimer, D. and Irena, K. (2008). Higher education entry of Turkish immigrant youth in Germany. International Journal of Comparative Sociology, 49, 127-151.

Levels, M., Dronkers, J. and Kraaykamp, G. (2008). Immigrant children's educational achievement in western countries. American Sociological Review, 73, 835-853.

Laganà, F. et al. (2013). National minorities and their representation in social surveys: which practices make a difference? Quality \& Quantity, 47, 1287-1314.

Mare, R. D. (1980). Social background and school continuation decisions. Journal of the American Statistical Association, 75, 295-305. 
Mood, C. (2010). Logistic regression: why we cannot do what we think we can do, and what we can do about it. European Sociological Review, 26, 67-82.

Müller, W. and Shavit, Y. (1998). The institutional embeddedness of the stratification process. In Shavit, Y. and Müller, W. (Eds.), From School to Work. Oxford: Clarendon Press, pp. 1-48.

Nezlek, J. B. (2008). An introduction to multilevel modeling for Social and Personality Psychology. Social and Personality Psychology Compass, 2, 842-860.

OECD (2006). Where Immigrant Students Succeed. Paris: OECD.

Orr, D. (2008). Social and Economic Conditions of Student Life in Europe. Bielefeld: Bertelsmann.

Orr, D., Gwosc, C. and Netz, N. (Eurostudent) (2011). Social and Economic Conditions of Student Life in Europe. Bielefeld: Bertelsmann.
Raudenbush, S. and Bryk, A. S. (2002). Hierarchical Linear Models, 2nd edn. Thousand Oaks: Sage Publications.

Söhn, J. (2011). Rechtsstatus und Bildungschancen. Wiesbaden: VS Verlag für Sozialwissenschaften.

Van de Werfhorst, H. G. and Mijs, J. J. B. (2010). Achievement inequality and the institutional structure of educational systems. Annual Review of Sociology, 36, 407-428.

Van de Werfhorst, H. G. and Van Tubergen, F. (2007). Ethnicity, schooling, and merit in the Netherlands. Ethnicities, 7, 4164-4144.

Zhou, M. and Bankston, C. L. III (1994). Social capital and the adaptation of the second generation. International Migration Review, 28, 821-845. 